\title{
Fault Ride-Through and Transient Stability Augmentation of Grid-Connected PV Station Using Virtual Synchronous Generator
}

\author{
Md. Kamrul Islam, Mohammad Abdul Mannan and Md. Rifat Hazari
}

\begin{abstract}
Due to the extensive integration of renewable energy sources (RESs), i.e., photovoltaic (PV) system, the future power system is developing into an inverter-based system from a dominated alternator-based power system. This massive penetration of inverter-based PV system reduced the system inertia and damping characteristics of the power grid, impacting the fault ride-through (FRT) capability and causes frequency instability. Therefore, this paper proposes a virtual synchronous generator (VSG) control mechanism of PV system inverter to augment FRT competency and frequency stability. The proposed VSG control system mimics the behavior of conventional power plants. To observe and evaluate the proposed controller behavior, simulation analyses were executed in the PSCAD/EMTDC software for both proposed and conventional controllers. The simulation results clearly indicate that the proposed VSG control system has sufficient damping characteristics to ensure FRT capability and frequency stability.
\end{abstract}

Keywords: fault ride-through (FRT), PI Controller, PV plant, virtual synchronous generator (VSG), transient stability.

\section{Introduction}

One of the scientist's fantasies that are becoming a reality is the commitment to green, cost-effective, and durable energy from the sunlight. Studies in this area progress and incorporates new findings regularly. There is the continued improvement of the PV market, and solar energy is integrated into the power grid on a vast range. In the recent decade, the charges of PV systems reduced continuously [1-3]. What's more, to enlarge the electricity market, several governments imposing and supporting renewable energy policies [4].

Hence, the PV market has grown tremendously in recent years. As per the market estimations, at the end of 2018, the implemented PV capacity was $520 \mathrm{GW}$ which would satisfy approximately $1.4 \mathrm{TW}$ within 2024. As per the 2019 PV status report, the latest prospects of $100 \%$ of renewable power particularly emphasized the significance of solar PV in achieving this target and in economically reducing $\mathrm{CO} 2$ in the

Md. Kamrul Islam is a master's student of the Department of EEE American International University-Bangladesh, Dhaka-1229, Bangladesh. Email: kamrulislamczs@gmail.com

Mohammad Abdul Mannan is a Professor and Director of the Department of EEE, American International University-Bangladesh, 408/1, Kuratoli, Khilkhet, Dhaka-1229, Bangladesh. Email: mdmannan@aiub.edu

Md. Rifat Hazari is an Assistant Professor of the Department of EEE, American International University-Bangladesh, 408/1, Kuratoli, Khilkhet, Dhaka-1229, Bangladesh. Email: rifat@aiub.edu energy field. In order to achieve a CO2-free electricity supply by 2050 the PV generating power of roughly $650 \mathrm{GW}$ must be raised to greater than $4 \mathrm{TW}$ by 2025 , and 21.9 TW by 2050 [5].

Ensuring grid stability and reliability has become a significant concern for network operators due to the high integration of PV systems in power grids [6]. Furthermore, PV systems have established medium voltage grid codes in recent decades, with suppliers mandating that these systems engage in and perform a prominent role in grid collapse situations [7].

To comply with these grid specifications, the PV system must satisfy the FRT performance criteria and remain in the grid-tied condition promptly after the disruption. Additionally, worldwide FRT standards have been employed to maintain the smooth operation of grids like PV. Hence, in the event of system collapse, the PV system will remain linked to the transmission network [8].

To enhance the FRT competence, numerous alternative auxiliary strategies can be imposed in the event of a network disruption, including supercapacitor [9], direct current (DC)-breaking chopper circuit [10], energy storage system (ESS) [11], series dynamic braking resistor (SDBR) [12], static synchronous compensator (STATCOM) [13]. Although the FRT competency can be ensured in [9-13], however, the overall cost of the system has risen.

In [14-15], several cascaded PI controllers are also used to augment the FRT competence and stability. However, the overall system may unstable during the transient period when the PV system's penetration ratio is equivalent to the conventional power plant.

In order to enhance the frequency stability, some researchers developed a battery storage system that also increases the installation cost [16-17].

On the other hand, researchers are currently focusing on inverter design based on the VSG concept [18]. The fundamental idea illustrated in Ref. [19] is to replicate the characteristics of a synchronous generator (SG) and also to provide damping and inertial support.

Further, the objective of VSG-powered techniques is to simulate the $\mathrm{SG}$ frequency control features for rotor inertia and system frequency modulation, in order to optimize the system's frequency stability. VSG executes power control and frequency modulation operations according to the power and voltage frequency controller [20-22]. A virtual inertia control approach depending on point of common coupling (PCC) frequency feedforward is suggested in [23] to 


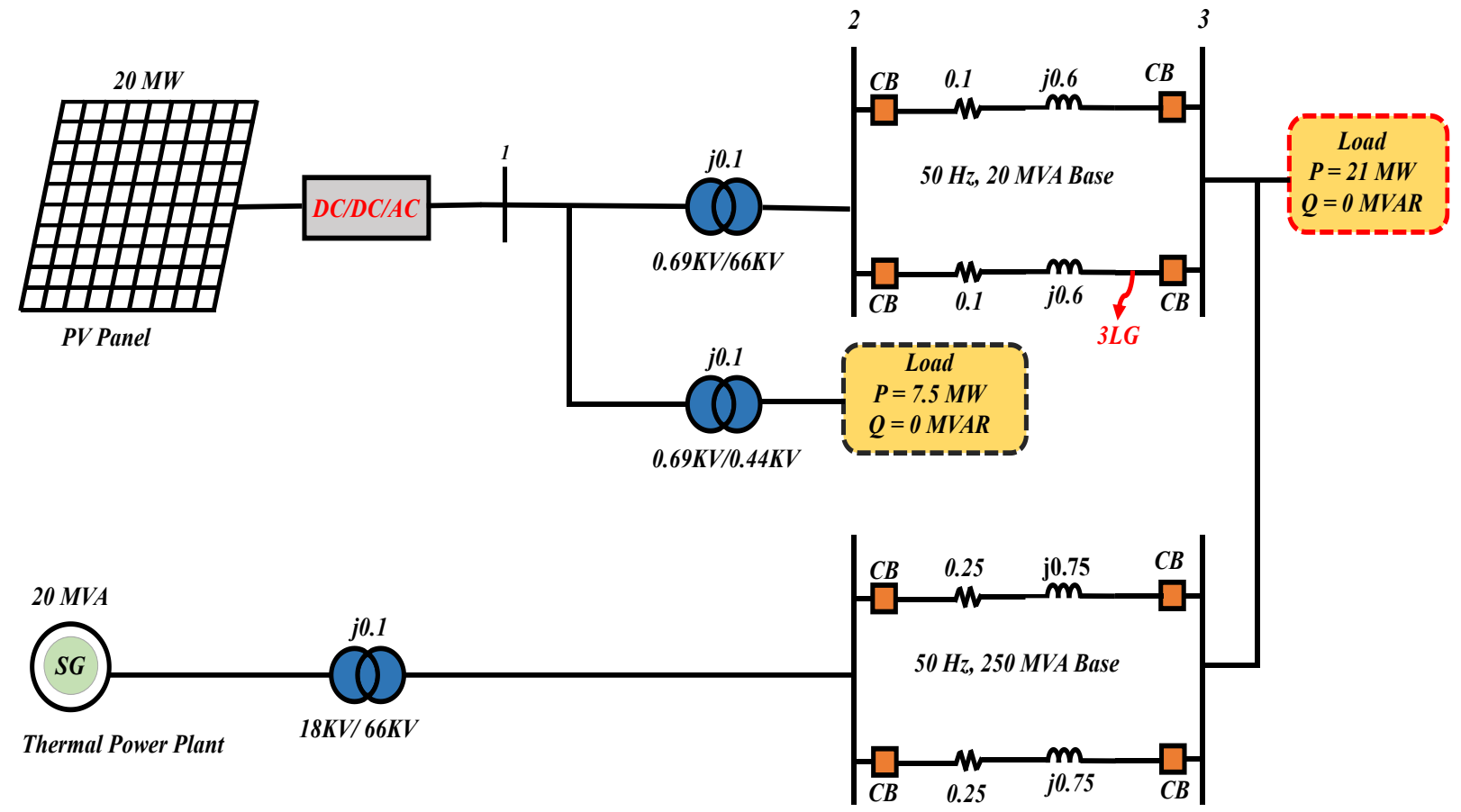

Fig. 1: Model of Power System.

resolve the issue of output power operations of VSG controlled grid-tied converters under grid frequency disturbance (GFD). Moreover, an innovative control strategy to maintain the power-angle stability of lowinertia micro-grids composed of distributed VSG units in accordance with the equal-area criteria is proposed in [24].

Consequently, most of these approaches are concentrated on the inverter control strategy ignoring the PV panel, maximum power point tracking (MPPT), and boost converter. Also, none of this research has studied the FRT compatibility and stability of the power grid when the penetration ratio of the PV system is close to the conventional power plant.

Therefore, the key aim of this research is to build a VSG-based control strategy that takes into account the PV panel to augment the PV station's FRT performance and frequency stability during high penetration of $\mathrm{PV}$. The proposed inverter control scheme mimics the behavior of mechanical governor, automatic voltage regulator (AVR), and damping characteristics of typical SG. Furthermore, the following evaluations have been conducted to justify the proposed work:

(1) The performance of a large-scale PV plant was examined in terms of FRT capability and frequency stability considering the most severe condition, which is the triple line-to-ground ( $3 \mathrm{LG}$ ) fault. The simulation shows that the proposed VSG control method has FRT competencies and can stabilize the system frequency.

(2) A comparison of the proposed VSG controller with the conventional control technique presented in Ref. [14] is performed. The simulation outcomes significantly demonstrate the proposed system's effectiveness and stability against Ref. [14].
The paper is categorized as per: The power system model is described in Section 2. PV power plant model is illustrated in Section 3. The proposed VSG control strategy is explained in Section 4. FRT criteria are discussed in Section 5. The simulation results and discussion are described in Section 6. Lastly, Section 7 depicted the conclusion.

\section{Power System Model}

The power system model used in this research is displayed in Fig. 1. The model consists of a PV power plant and a thermal power plant. The PV plant has a capacity of $20 \mathrm{MW}$. A $0.69 \mathrm{kV} / 66 \mathrm{kV}$ transformer and a double circuit transmission line connect the PV plant to the grid.

Moreover, a local load is connected through a 0.69 $\mathrm{kV} / 0.44 \mathrm{kV}$ transformer to the terminal of the PV plant. As illustrated in Fig. 2, the IEEE standard AC4A solidstate exciter is implemented as an exciter technique for SG [25]. The specifications of the AC4A exciter are presented in Appendix. The governor system model for thermal power plants is presented in Fig. 3 [25].

An automated control mechanism is provided for SG by the AGC architecture. The integrated AGC control is displayed in Fig. 4. For $K i$, the integral gain is set at 6.

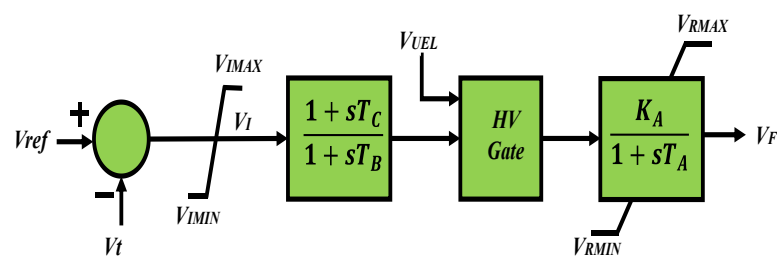

Fig. 2: AC4A exciter Technique. 


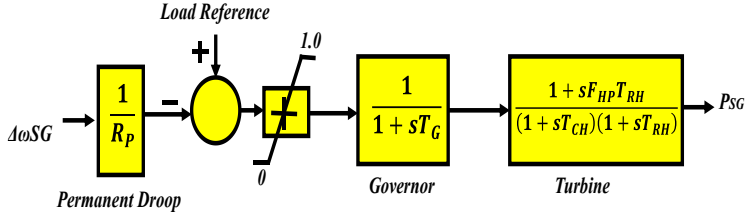

Fig. 3: Thermal Governor Model.

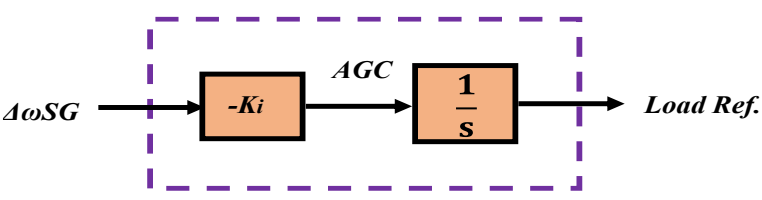

Fig. 4: AGC Integral controller.

\section{PV Power Plant Model}

\subsection{Design of PV Plant}

The single diode equivalent circuit of the designed PV module is represented in Fig. 5. In this paper, a single diode model is employed, which is a rapid, easy, and accurate model [26]. Moreover, a single diode, current source, and two resistors are linked in series and parallel to mimic the PV panel in this design.

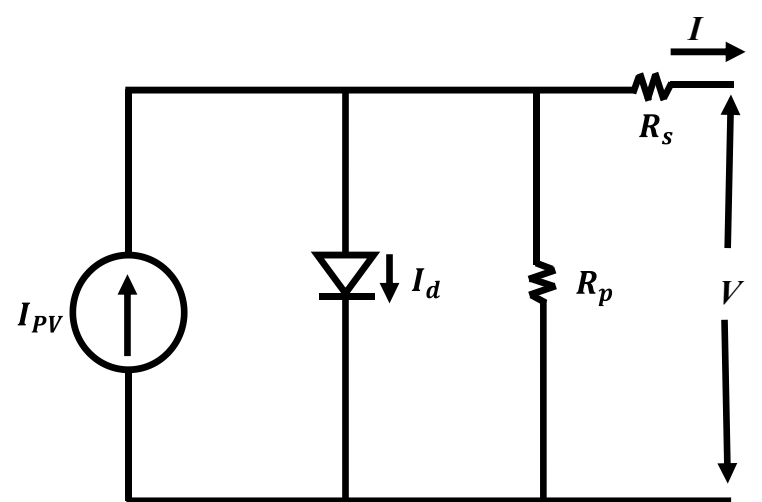

Fig. 5: Single Diode Equivalent Model of PV Module.

The integrated structure of a PV farm composed of various PV modules [26-28]:

$$
\begin{aligned}
I=N_{P} I_{P V}-N_{P} I_{0}\left[\exp \left(\frac{V+R_{S}\left(\frac{N_{M}}{N_{P}}\right) I}{N_{M} a V_{t}}\right)-1\right] \\
-\frac{V+R_{S}\left(\frac{N_{M}}{N_{P}}\right) I}{R_{P}\left(\frac{N_{M}}{N_{P}}\right)}
\end{aligned}
$$

Here, $N_{P}=$ number of parallel modules attached in a string, $N_{M}=$ number of series modules attached in a string. Fig. 6 displays the $I$ vs $V$ and $P$ vs $V$ characteristics curves for a $20 \mathrm{MW}$ PV system. The Appendix contains all data on such a 20 MW PV plant.
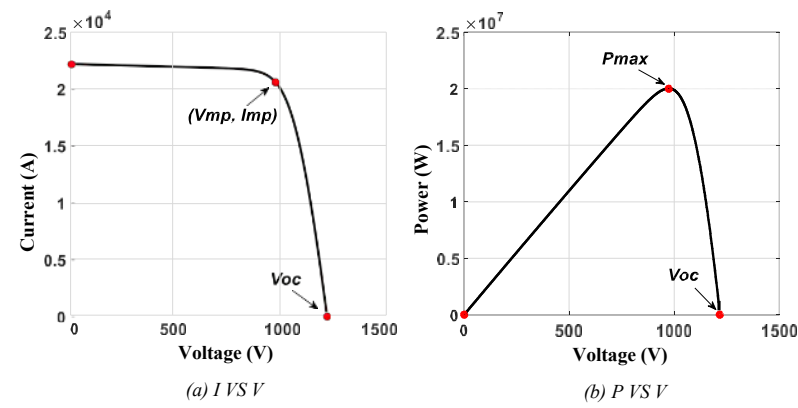

Fig. 6: 20 MW PV Power Plant Characteristics

Curve.

\subsection{Control Technique of PV Power Plant}

The control strategy and architecture of the PV plant are displayed in Fig. 7. A PV module, a DC/DC step-up converter, and a DC/AC inverter are all components of the system. Here the insulated gate bipolar transistors (IGBTs) are deployed in both the boost converter controllers and grid side inverter controller those independently control the converter and inverter. Moreover, the pulse width modulation (PWM) approach is performed by both converters in this paper. For modeling of the DC distribution system [29], the parameters of TOP SOLAR XZ-K (AS) $1 \times 300 \mathrm{~mm}^{2}$ cable [30] are adopted.

To augment the output voltage level and achieve the maximum power from the PV station the DC/DC stepup converter is utilized. In addition, the output voltage in the PV plant is employed for defined irradiation and temperature at a fixed value. The fractional open-circuit voltage $(V o c)$ approach is employed to optimize the power of the system in this research. The voltage of $V m p$ at maximum power is proportional to Voc. Hence, the categorization of the relationship is the following:

$$
V_{m p}=K_{m p} V_{o c}
$$

Here, the proportionality constant Kmp is employed with a value of 0.8023 for the KC200GT solar panel [28].

Consequently, the DC-DC boost converter reference duty cycle (Dref) can be expressed as:

$$
D_{\text {ref }}=1-\frac{N_{M} K_{m p} V_{\text {oc_pilot }}}{V_{0}}
$$

Here, Voc pilot denotes the voltage of the pilot module in the open-circuit condition and $V o$ denotes the output of the step-up converter. The DC-DC step-up converter controlling mechanism is displayed in Fig. 8 [14].

When a grid fault happens the DC-link voltage $(V d c)$ increases to excessively high levels. As a result, the DC power entering from the PV system cannot be delivered into the grid. Hence, the DC/DC boost converter controller adopts an auxiliary control technique as illustrated in Fig. 8. 


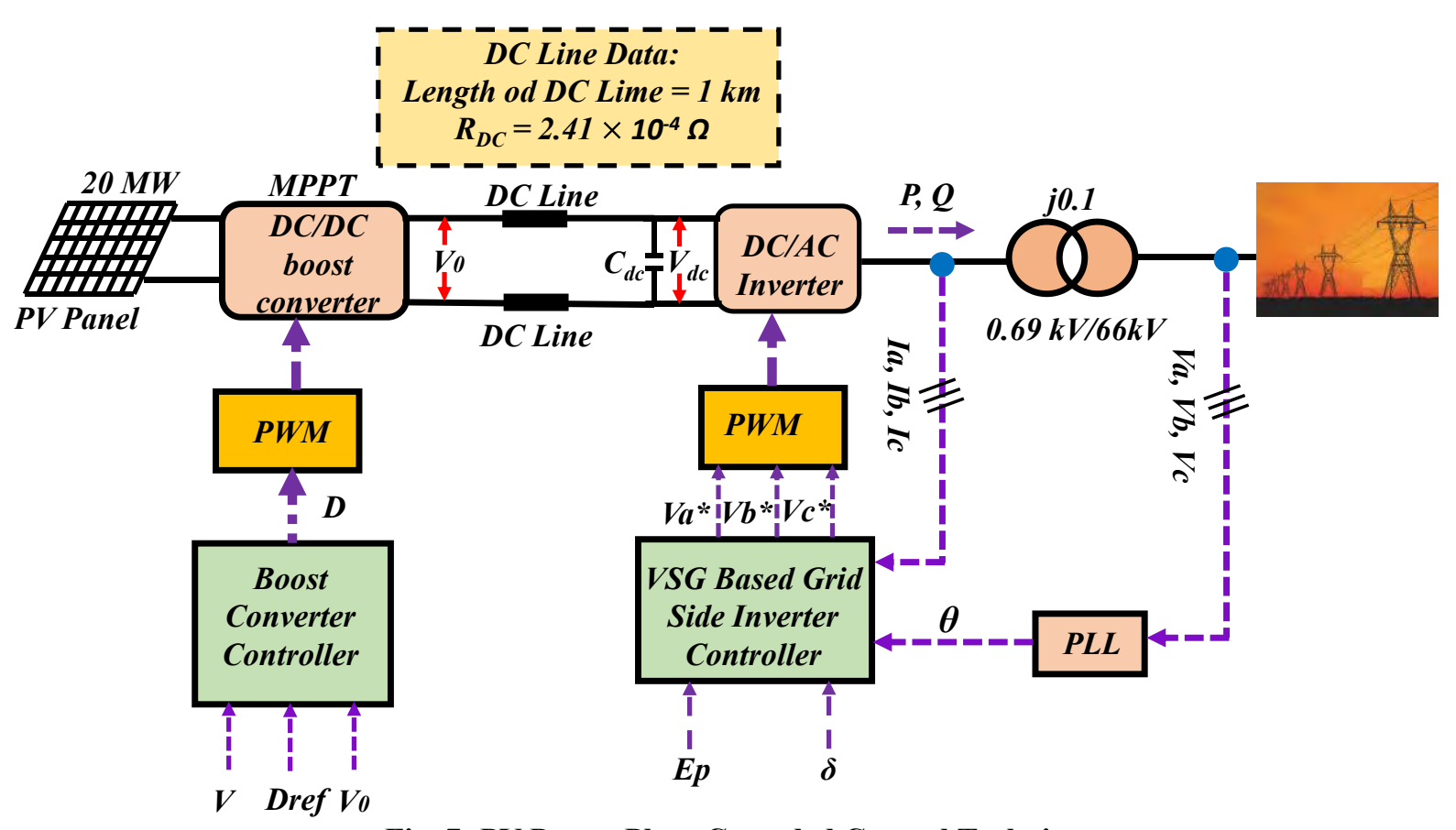

Fig. 7: PV Power Plant Cascaded Control Technique.

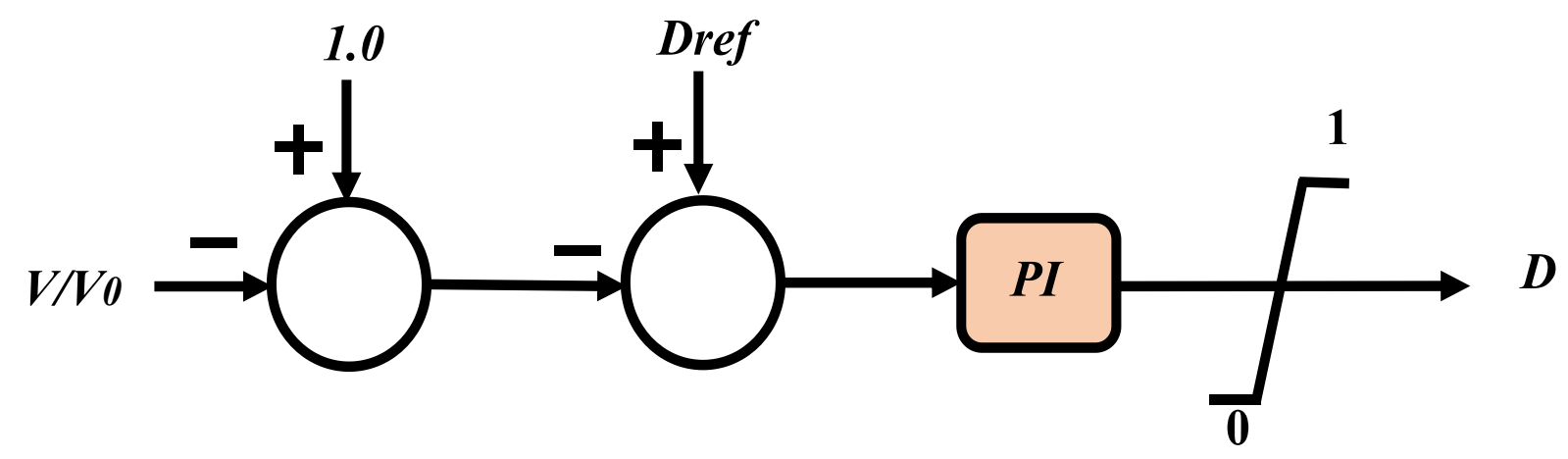

Fig. 8: Control Technique of DC-DC Converter Controller.

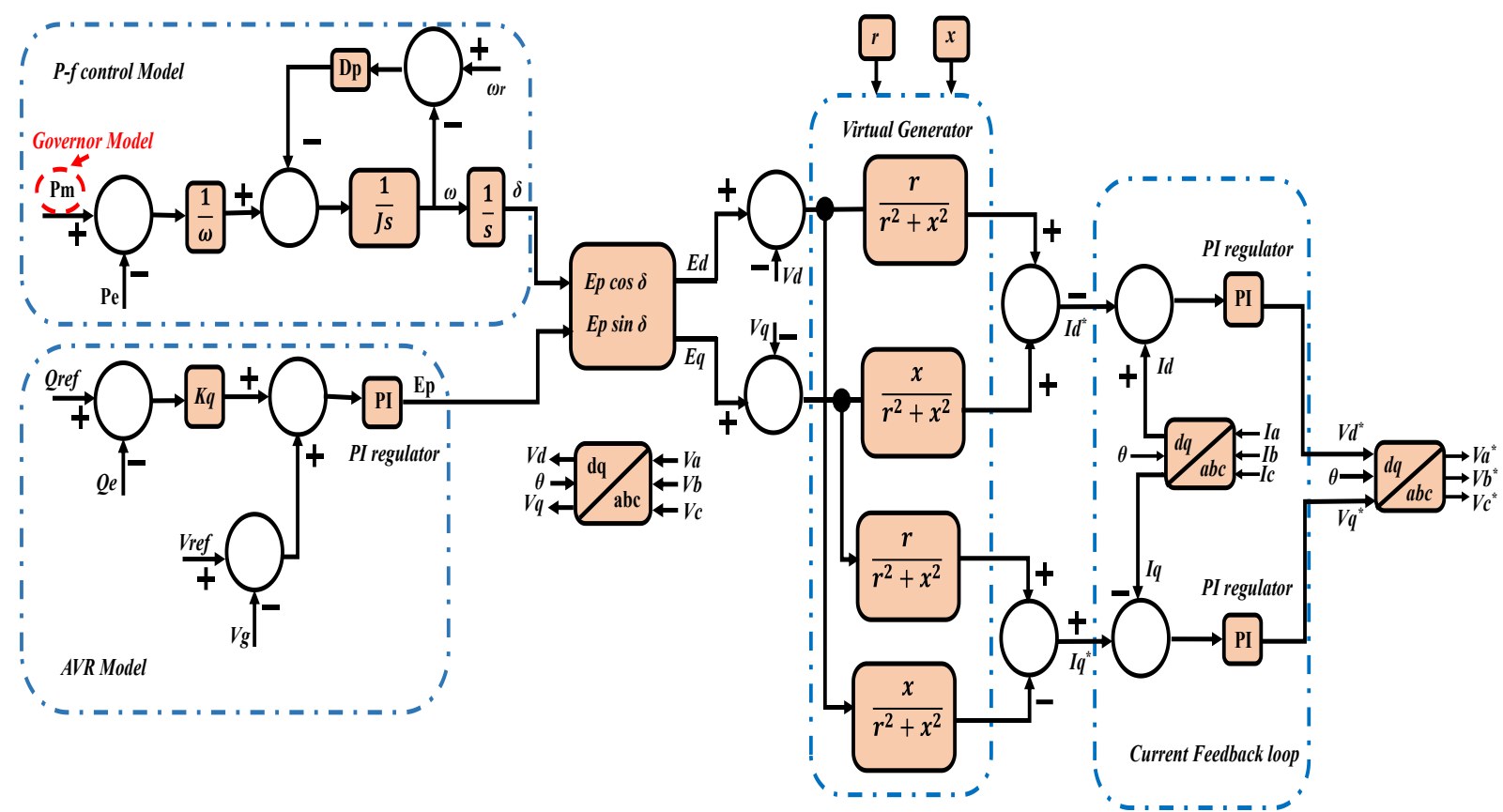

Fig. 9: Proposed VSG Control Strategy. 
In the PV system, the $\mathrm{DC}-\mathrm{AC}$ inverter converts the $\mathrm{DC}$ voltage to three phase $\mathrm{AC}$ voltage. The proposed grid side inverter controller based on VSG is represented in Fig. 9. Section 4 illustrates the complete model of the VSG control system.

\section{Proposed VSG Control Scheme}

The overall proposed VSG control technique is represented in Fig. 9. The control system involves the governor model, AVR model, virtual generator model, and current feedback loop.

\subsection{Model of VSG}

Fig. 10 represents the VSG impedance model. Here, $r$ denotes the armature resistance and $\mathrm{x}$ denotes the generator synchronous reactance. Moreover, Ep denotes the electromotive force generated by the field windings. The phase displacement between the rotor and the grid is represented by $\delta$, also known as the load angle. $V g$ denotes the grid voltage, and $V d$ and $V q$ represent its projections to the $\mathrm{d}$ and $\mathrm{q}$ axis. The armature currents $I_{d}{ }^{*}$ and $I_{q}{ }^{*}$ are represented by the following equation [31]. These are employed for controlling the current inverter command.

$$
\begin{aligned}
& {\left[\begin{array}{l}
I_{d}^{*} \\
I_{q}^{*}
\end{array}\right]=Y\left\{\left[\begin{array}{l}
E_{d} \\
E_{q}
\end{array}\right]-\left[\begin{array}{l}
V_{d} \\
V_{q}
\end{array}\right]\right\}} \\
& Y=\frac{1}{r^{2}+x^{2}}\left[\begin{array}{cc}
r & x \\
-x & r
\end{array}\right] \\
& \bigcup\left[\begin{array}{l}
E_{d} \\
E_{q}
\end{array}\right]=E_{p}\left[\begin{array}{l}
\cos \delta \\
\sin \delta
\end{array}\right]
\end{aligned}
$$

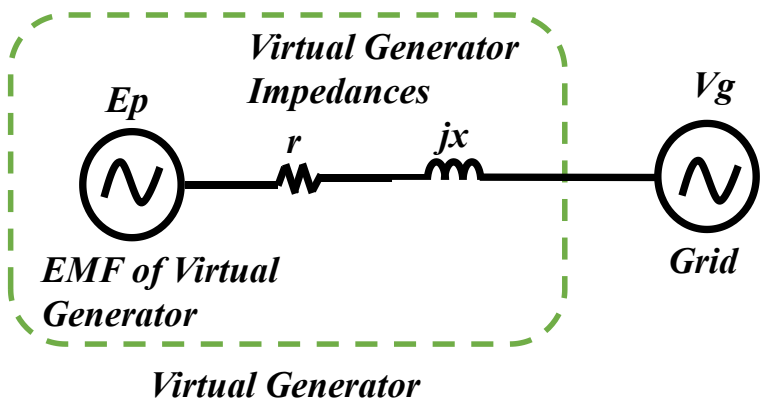

Fig. 10: VSG Impedance Model.

\subsection{Active Power-Frequency Control Scheme}

The VSG can be employed to regulate the frequency of the grid. As illustrated in Fig. 9, the VSG control in the inverter enables primary frequency management by integrating an appropriate amount of power through an inertial response. The VSG algorithm determines the load angle $(\delta)$ using the swing equation, which is based on the active power change. The main mechanism of the VSG is expressed by the equations [32-34]:

$$
\begin{aligned}
& \left(P_{m}-P_{e}\right) / \omega-D_{p}\left(\omega-\omega_{r}\right)=J \frac{d \omega}{d t} \\
& \frac{d \delta}{d t}=\omega
\end{aligned}
$$

Here, $P e$ and $P m$ represent the instantaneous active power and reference active power (as in a synchronous generator), sequentially. Droop constant, inertia, reference angular frequency, and angular frequency are displayed by $D p$ and $J, \omega r$ and $\omega$, respectively. Additionally, a governor model, depicted in Fig. 11, is implemented to regulate the input power command depending on frequency variation.

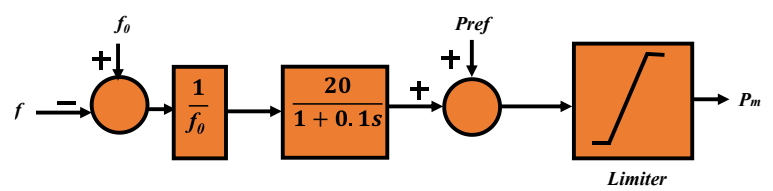

Fig. 11: Governor Model.

\subsection{AVR Model}

The reactive power-voltage control can be designed using a basic excitation technique of the SG, and the control schematic is depicted in Fig. 9. The below equation reflects the output voltage:

$$
E_{p}=\left\{\left(Q_{\text {ref }}-Q_{e}\right) K_{q}+\left(V_{\text {ref }}-V_{g}\right)\right\}\left(K_{p}+\frac{K_{i}}{s}\right)
$$

Here, the reference reactive power, instantaneous reactive power, reference voltage, and terminal voltage are represented by Qref, Qe, Vref, and Vg, accordingly. The reactive droop control is denoted by $K q$. Besides, $K p$ and $K i$ are the proportional and integral gains of the PI controller, accordingly.

\subsection{Current Feedback Loop}

The current feedback loop is composed of two PI controllers as presented in Fig. 9. These PI controllers compensate the $\mathrm{d}$ and $\mathrm{q}$ axis current to generate the reference $d$ and $q$ axis voltage. The necessary angle of transformation is obtained from the grid system.

\section{Specification of FRT Capability}

Fig. 12 demonstrates the FRT specifications for PV stations [8]. The PV stations must be attached to the electricity network if the voltage drop remains at the required root mean square (RMS) value and the required period is also illustrated in Fig 12.

However, the PV plants must be operative without tripping, if the connection point voltage restores to $90 \%$ of the rated voltage within $1.5 \mathrm{~s}$ after the voltage collapse. 


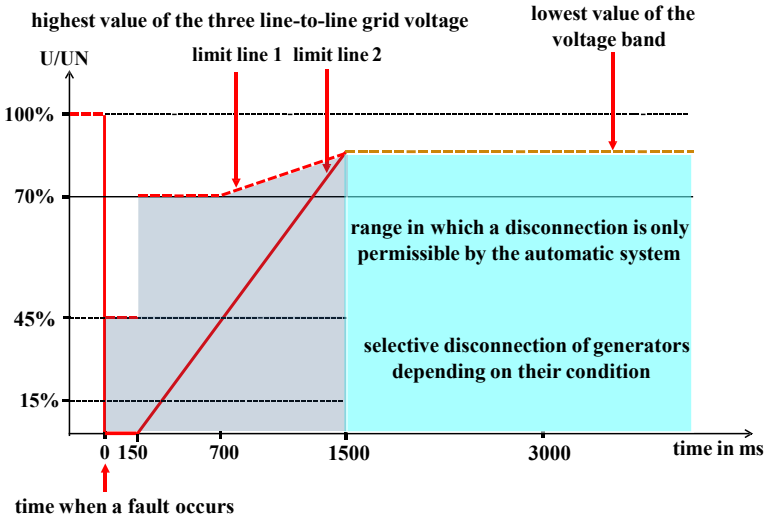

Fig. 12: Specification of FRT.

\section{Simulation Analysis and Discussion}

The model of the power system depicted in Fig. 1 is incorporated to conduct the simulation. It is considered that the frequency is $50 \mathrm{~Hz}$. Furthermore, the simulation time is $10 \mathrm{~s}$, the time step is $5.0 \mu \mathrm{s}$ and the channel plot step is $5000 \mu \mathrm{s}$ for ensuring effective performance. In addition, $3 \mathrm{LG}$ is performed in the main system as a severe network interruption to justify the effectiveness of the proposed control scheme. Moreover, the fault conditions as follows: the fault occurs at $0.1 \mathrm{~s}$, the duration of fault $0.1 \mathrm{~s}$, circuit breakers (CBs) opened at 0.2 and reclosed at $1 \mathrm{~s}$.

Two independent case studies are conducted to determine the effective PV control system for enhancing FRT performance and transient stability.

Case 1: Conventional Cascaded Control of PV system inverter [14].

Case 2: Proposed VSG Control method of PV system inverter.

The output voltage response of the PV plant for the two separate cases is depicted in Fig. 13, where it is visible that case 2 has a higher performance in both cases. Furthermore, case 2 also demonstrates the lowest voltage dips after even a $3 \mathrm{LG}$ fault. This is accomplished by injecting a sufficient quantity of reactive power during the transient period in case 2 compared to case 1 which is illustrated in Fig. 14. Moreover, during a $3 \mathrm{LG}$ fault, the PV inverter in case 1 only supplies a small quantity of reactive power. As a result, the PV plant's terminal voltage struggles to restore its nominal condition.

In case 1 the error cannot be adjusted by the outer loop controller. So, it does not provide an adequate amount of reactive power. As a result, the system is unstable in case 1 . On the other hand, in case 2 the AVR model can control the reactive power because it can adjust the error. Therefore, the system becomes stable.

Fig. 15 depicts the PV plant's active power response where case 2 shows to be a stable performance in both cases. Moreover, in case 1 the fluctuation of active power response is observed in steady-state and transient conditions.

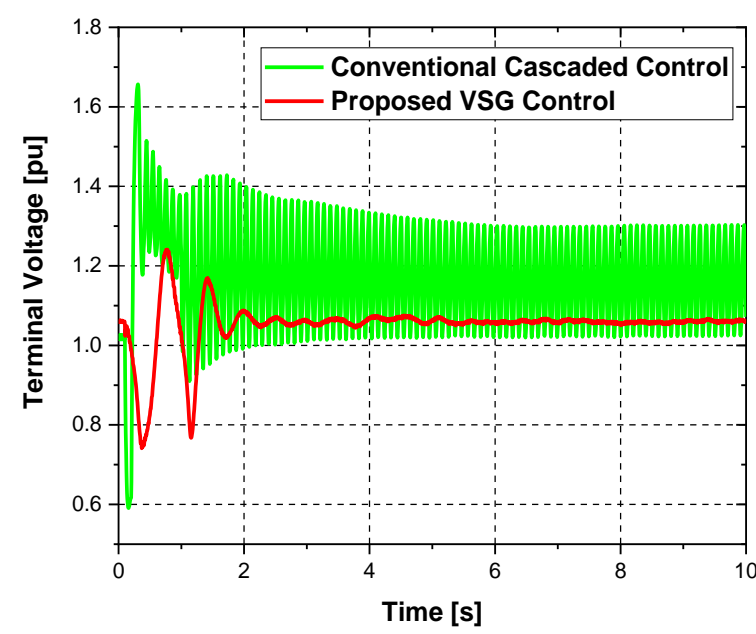

Fig. 13: Terminal Voltage Response of PV Plant.

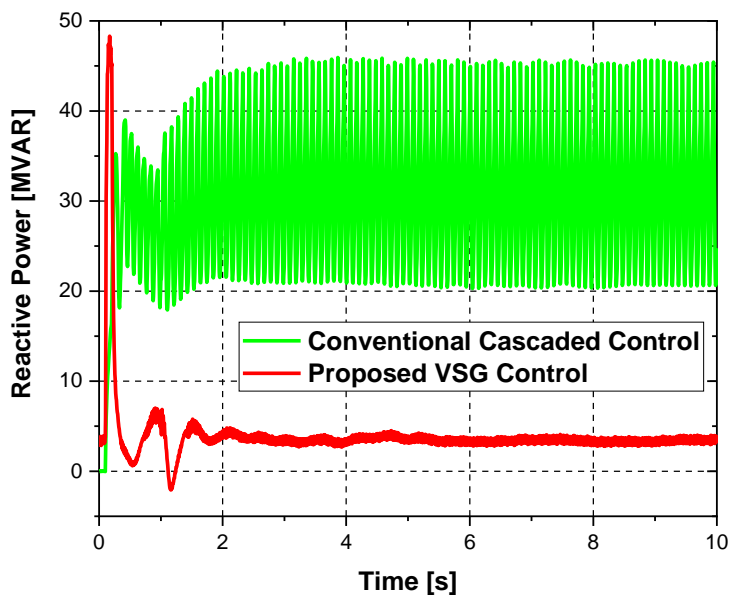

Fig. 14: Reactive power Response of the PV Plant.

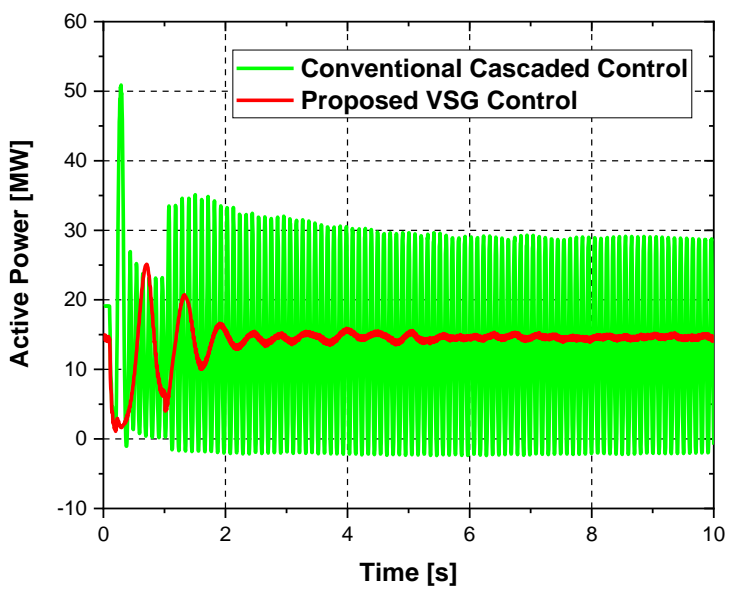

Fig. 15: Active power Response of the PV Plant. 


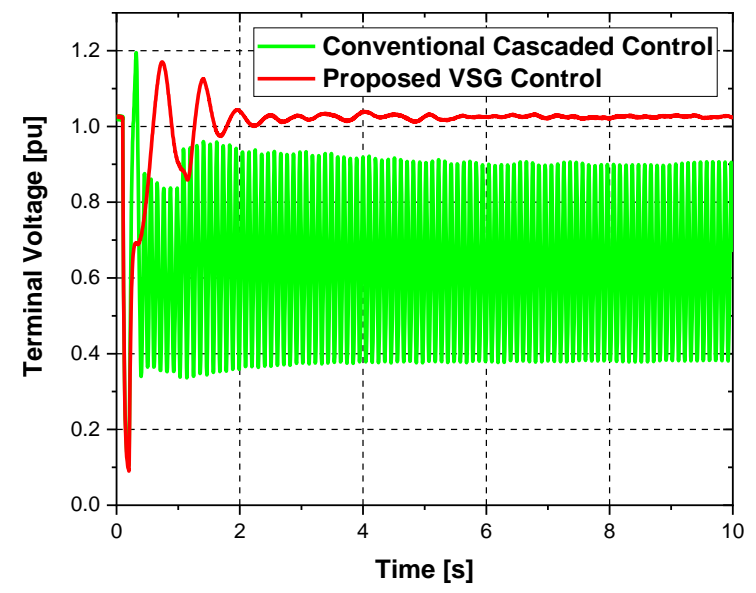

Fig. 16: Terminal Voltage Response of SG.

However, the terminal voltage of SG is more stable in case 2 than in case 1 which is presented in Fig. 16. The reactive power response of $\mathrm{SG}$ is displayed in Fig. 17. After the fault, the active power response of SG is more stable in case 2 which is depicted in Fig. 18. Further, in case 1 the variations of active power in SG are observed throughout the steady-state and transient state.

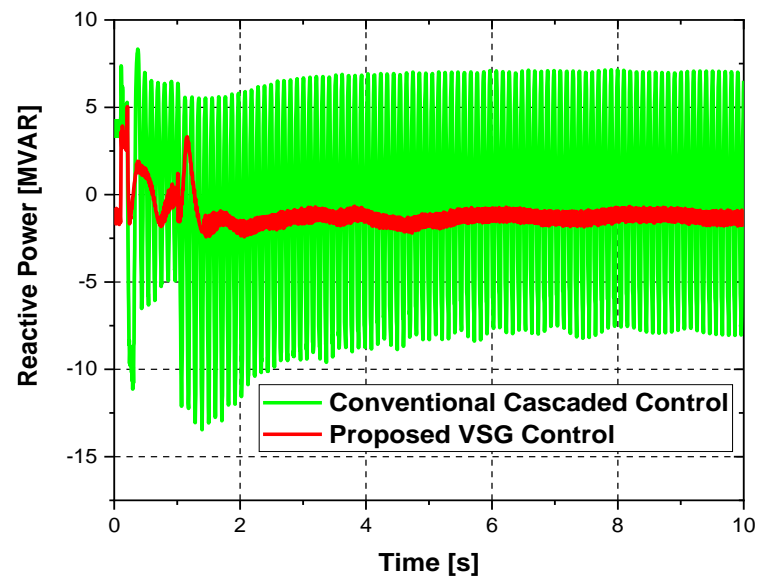

Fig. 17. Reactive Power Response of SG.

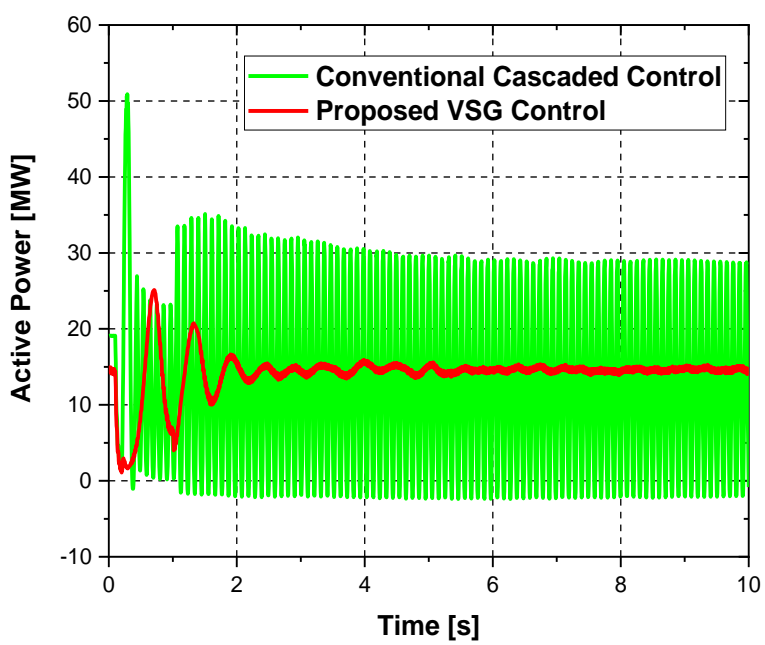

Fig. 18: Active Power Response of SG.
The rotor speed is reduced significantly in both cases, and the rotor speed of SG in case 2 is quite stable than in case 1, as illustrated in Fig. 19. The frequency response of both cases is displayed in Fig. 20 where it has been seen clearly that the frequency response is more stable in case 2 than case 1. Depending upon the designed governor model that showed in Fig. 11 the frequency deviation has been adjusted in case 2 . Hence, the sufficient amount of active power is supplied during the transient period and the system becomes stable. On the other hand, in case 1 the adequate amount of active is not provided. Hence, frequency response crosses the acceptance level which makes the system unstable.

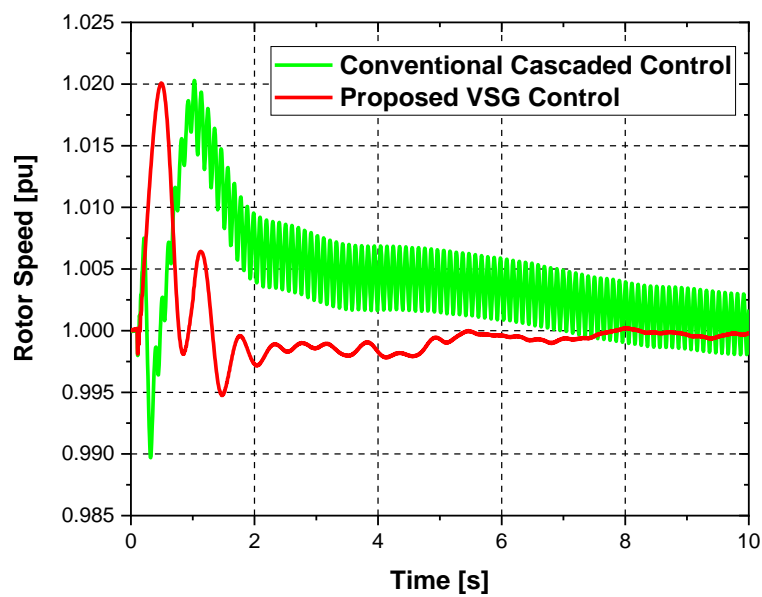

Fig. 19: Rotor Speed Response of SG.

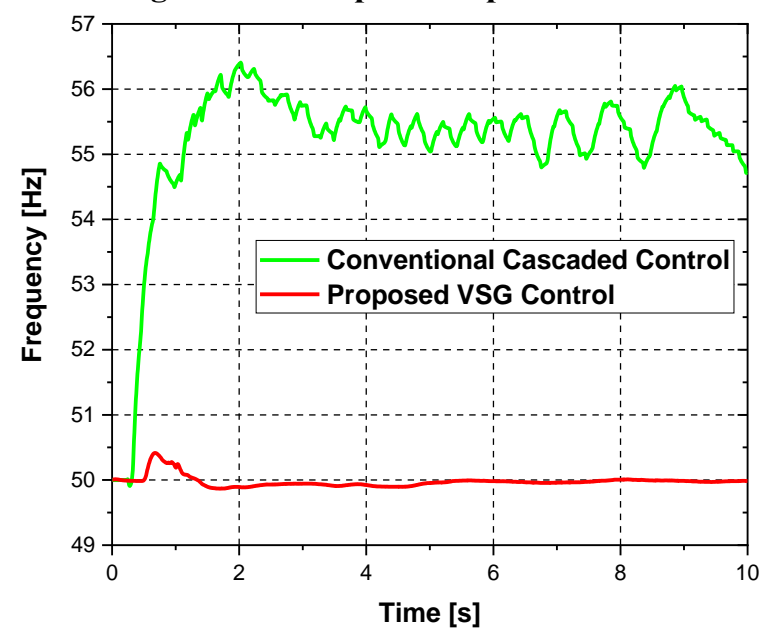

Fig. 20. Frequency Response.

Based on the findings, it is revealed that the proposed VSG controller could successfully stabilize the grid-connected PV station during transient periods as well as enhance the FRT augmentation.

\section{Conclusion}

In this research, a suitable VSG-based inverter control mechanism of PV system is developed to enhance FRT competence and frequency stability of power grid. Detailed design of the power system, PV system and proposed VSG system are sufficiently presented in the paper. Finally, two different control strategies are being investigated in simulation analysis 
to enhance FRT performance and stability competence in a grid-tied PV system with conventional power plants. As per the FRT grid code requirements, the proposed control techniques can restore the grid side voltage within $1.5 \mathrm{~s}$. Moreover, by using the governor model, AVR model, VSG model, and current feedback loop it is possible to increase system inertia and damping characteristics during the most severe fault case (3LG). A comparative study between conventional and proposed control schemes has been analyzed that reveals the proposed control scheme is capable of incorporating sufficient damping characteristics to ensure FRT efficacy and frequency stability.

\section{References}

[1] M. H. Qais, H. M. Hasanien, S. Alghuwainem, and A. S Nouh, "Coyote optimization algorithm for parameters extraction of three-diode photovoltaic models of photovoltaic modules," Energy, vol. 187, p. 116001, 2019.

[2] G. Lammert, D. Premm, L. D. Ospina, J. C. Boemer, M. Braun, and T. Van Cutsem, "Control of Photovoltaic Systems for Enhanced Short-Term Voltage Stability and Recovery," IEEE Transactions on Energy Conversion, vol. 34, no. 1, pp. 243-254, 2019.

[3] A. Mojallal and S. Lotfifard, "Enhancement of Grid Connected PV Arrays Fault Ride Through and Post Fault Recovery Performance," IEEE Transactions on Smart Grid, vol. 10, no. 1, pp. 546-555, 2019.

[4] Trends in Photovoltaic Applications Survey report of selected IEA countries between 1992 and 2009. Available online: https://iea-pvps.org/wpcontent/uploads/2020/01/tr_2009 neu.pdf [accessed on 04 June 2021]

[5] Jaeger-Waldau, A., PV Status Report 2019, EUR 29938 EN, Publications Office of the European Union, Luxembourg, 2019, ISBN 978-92-76-12608-9, doi:10.2760/326629, JRC118058

[6] D. L. Brooks and M. Patel, "Panel: Standards \& interconnection requirements for wind and solar generation NERC Integrating Variable Generation Task Force," 2011 IEEE Power and Energy Society General Meeting, 2011.

[7] G. J. Kish, "Addressing future grid requirements for distributed energy resources," M.Sc. thesis, Dept. Elect. Comput. Eng., Univ. Toronto, Toronto, ON, Canada, 2011.

[8] E. ON NETZ GmbH (2006) Grid Connection Regulation for High and Extra High Voltage. E. ON NETZ GmbHs, Essen, Germany.

[9] H. Tian, F. Gao, and C. Ma, "Novel low voltage ride through strategy of single-stage grid-tied photovoltaic inverter with supercapacitor coupled," Proceedings of The 7th International Power Electronics and Motion Control Conference, 2012

[10] A. Q. Al-Shetwi and M. Z. Sujod, "Modeling and Control of Grid-Connected Photovoltaic Power Plant With Fault Ride-Through Capability," Journal of Solar Energy Engineering, vol. 140, no. 2, 2017.

[11] B.V.V.N. Manikanta, G. Kesavarao, T. Shefali, "LVRT of grid -connected PV system with energy storage," Int. J. Control Theory Appl. vol. 10, pp. 75-86, 2017.

[12] M. K. Hossain and M. H. Ali, "Low voltage ride through capability enhancement of grid connected PV system by SDBR," 2014 IEEE PES T\&D Conference and Exposition, 2014.

[13] I. A. Ethmane, A. K. Mahmoud, M. Maaroufi, and A. Yahfdhou, "Transient stability enhancement of statcom integration in power grid," Indonesian Journal of Electrical Engineering and Computer Science, vol. 16, no. 2, p. 553, 2019.

[14] S. M. Istiaque Mahmud, M. A. Mannan and M. R. Hazari, "LVRT Performance Analysis and Transient Stability Augmentation of a Grid-Tied PV System," 2021 2nd International Conference on Robotics, Electrical and Signal Processing Techniques (ICREST), pp. 48-52, 2021.

[15] A. Ahmed, M. R. Hazari, E. Jahan, and M. A. Mannan, "A Robust Control Strategy to Improve Low Voltage RideThrough of a Grid-Connected Photovoltaic System," International Journal of Power and Energy Systems, vol. 41, no. 1,2021

[16] A. Jawad, S. A. Naim, C. Saha and N. -A. Masood, "Frequency Stability Enhancement of a Large-Scale PV Integrated Grid," 2020 11th International Conference on Electrical and Computer Engineering (ICECE), pp. 290-293, 2020.

[17] E. Munkhchuluun, L. Meegahapola and A. Vahidnia, "Optimal Battery Sizing for Large-Scale Solar-PV Generation to Improve Frequency Stability," 2019 29th Australasian Universities Power Engineering Conference (AUPEC), pp. 1-6, 2019.

[18] H. Bevrani, T. Ise, and Y. Miura, "Virtual synchronous generators: A survey and new perspectives," International Journal of Electrical Power \& Energy Systems, vol. 54, pp. 244-254, 2014.

[19] K. Shi, W. Song, P. Xu, R. Liu, Z. Fang, and Y. Ji, "LowVoltage Ride-Through Control Strategy for a Virtual Synchronous Generator Based on Smooth Switching," IEEE Access, vol. 6, pp. 2703-2711, 2018.

[20] R. Rajan and F. M. Fernandez, "Power control strategy of photovoltaic plants for frequency regulation in a hybrid power system," International Journal of Electrical Power \& Energy Systems, vol. 110, pp. 171-183, 2019.

[21] X. Quan, X. Zhao, L. Zhang, R. Xu, Y. Lei, and A. Q. Huang, "Novel power control of voltage-controlled inverters for grid inertia support," 2019 IEEE Applied Power Electronics Conference and Exposition (APEC), 2019.

[22] A. Belila, Y. Amirat, M. Benbouzid, E. M. Berkouk, and G. Yao, "Virtual synchronous generators for voltage synchronization of a hybrid pv-diesel power system," International Journal of Electrical Power \& Energy Systems, vol. 117, p. 105677, 2020.

[23] W. Sheng, Y. Wang, B. Liu, S. Duan, and M. Wu, "Virtual synchronous generator strategy for suppressing output power fluctuation without additional energy storage," IET Power Electronics, vol. 13, no. 3, pp. 602-610, 2020.

[24] K. M. Cheema, A. H. Milyani, A. M. El-Sherbeeny, and M. A. El-Meligy, "Modification in active power-frequency loop of virtual synchronous generator to improve the transient stability," International Journal of Electrical Power \& Energy Systems, vol. 128, p. 106668, 2021.

[25] P. Kundur, "Power System Stability \& Control," McGraw-Hill Inc.

[26] H. M. Hasanien, "An adaptive control strategy for low voltage ride through capability enhancement of gridconnected photovoltaic power plants." IEEE Transactions on power systems 31, no. 4 (2015): 3230-3237.

[27] G. M. Islam, A. Al-Durra, S. M. Muyeen, and J. Tamura, "A robust control scheme to enhance the stability of a gridconnected large scale photovoltaic system," PES T\&D 2012, 2012.

[28] H. M. Hasanien, "Shuffled Frog Leaping Algorithm for Photovoltaic Model Identification," IEEE Transactions on Sustainable Energy, vol. 6, no. 2, pp. 509-515, 2015.

[29] M. Starke, "DC distribution with fuel cells as distributed energy resources," Ph.D. dissertation, Dept. Electric. Eng., Univ. Tennessee, Knoxville, 2009. 
[30] Cables for photovoltaic solar installations. [Online]. Available:

www.elesis.gr/php/download.php?file=solar_cables_present ation.pdf [accessed on 5 June 2021].

[31] Y. Hirase, K. Abe, K. Sugimoto, and Y. Shindo, "A gridconnected inverter with virtual synchronous generator model of algebraic type," Electrical Engineering in Japan, vol. 184, no. 4, pp. 10-21, 2013.

[32] R. K. Sarojini, K. Palanisamy, P. Sanjeevikumar, and J. B. H. Nielsen, "Inertia emulation control technique based frequency control of grid-connected single-phase rooftop photovoltaic system with battery and supercapacitor," IET Renewable Power Generation, vol. 14, no. 7, pp. 1156-1163, 2020.

[33] J. Meng, Y. Wang, J. Peng, L. Xu, and J. Yin, "Flexible Virtual Synchronous Generator Control for Distributed Generator with Adaptive Inertia," Electric Power Components and Systems, vol. 47, no. 1-2, pp. 128-140, 2019.

[34] J. Alipoor, Y. Miura and T. Ise, "Power System Stabilization Using Virtual Synchronous Generator With Alternating Moment of Inertia," in IEEE Journal of Emerging and Selected Topics in Power Electronics, vol. 3, no. 2, pp. 451-458, 2015.

\section{Appendix}

Table A1: Values of IEEE Type AC4A Exciter.

\begin{tabular}{|c|c|}
\hline Parameter & Value \\
\hline$R_{P}$ & 0.06 \\
\hline$T_{G}$ & $0.3 \mathrm{sec}$ \\
\hline$T_{C H}$ & $0.2 \mathrm{sec}$ \\
\hline$T_{R H}$ & $8.0 \mathrm{sec}$ \\
\hline$F_{H P}$ & 0.4 \\
\hline
\end{tabular}

Table A2: Specifications of a 20 MW PV Station.

\begin{tabular}{|c|c|}
\hline Parameter & Value \\
\hline$P \max$ & $20 \mathrm{MW}$ \\
\hline$V m p$ & $973.1 \mathrm{~V}$ \\
\hline$I m p$ & $20580 \mathrm{~A}$ \\
\hline$N m$ & 37 \\
\hline$N_{P}$ & 2704 \\
\hline
\end{tabular}

Md. Kamrul Islam received his B.Sc. Engg. Degree in

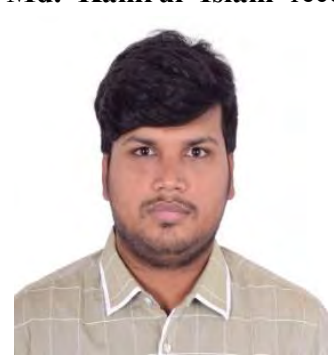
Electrical and Electronic Engineering (EEE) from American International University-Bangladesh (AIUB) in 2020. Recently, he is completing his M.Sc. Engg. Degree in Electrical and Electronic Engineering (EEE) from American International University-Bangladesh (AIUB). Currently, he is working as a Teaching Assistant (TA) in the Department of Electrical and Electronic Engineering under Faculty of Engineering at AIUB. Moreover, he is working as Team Captain of AIUB ROBOTIC CREW since 2019. His research interests are based on Renewable Energy, Power Electronics, Electrical Vehicles, Virtual Synchronous Generator, Microgrid, and Robotics. He is a graduate student member of IEEE.
Mohammad Abdul Mannan was born in Laxmipur,

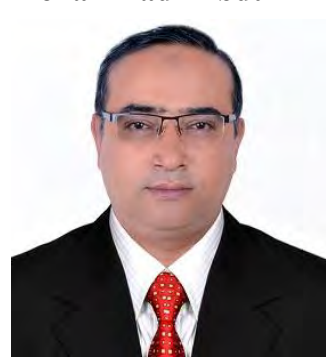
Bangladesh on January 01, 1975. $\mathrm{He}$ received his B. Sc. Eng. Degree from Rajshahi University of Engineering and Technology (RUET former BITR), Bangladesh, in 1998, and Masters of Eng. and Dr. of Eng. degrees from Kitami Institute of Technology, Japan, in 2003 and 2006 respectively, all in electrical engineering. He then joined in the American International University Bangladesh (AIUB) as an Assistant professor in May 2006. He served in AIUB as an Associate Professor from December 2013 to November 2016. Now he is working as a Professor and Director of the Faculty of Engineering in AIUB. His research interests include electric motor drive, power electronics, power system, wind generation system and control of electric motor, power electronic converters, power system, and wind generation system. Prof. Dr. Mannan is a member of the IEB and IEEE.

Md. Rifat Hazari received his B.Sc. Engg. and M.Sc. Engg.

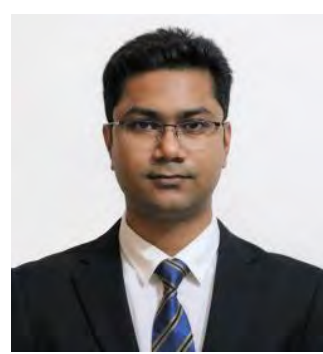
Degrees in Electrical and Electronic Engineering from American International University-Bangladesh (AIUB) in August 2013 and December 2014, respectively and Ph.D. Degree in Energy Engineering from Kitami Institute of Technology (KIT), Japan, in March 2019. He served as a Lecturer in Electrical and Electronic Engineering department at AIUB. Currently, he is working as an Assistant Professor in the Electrical and Electronic Engineering department at AIUB. He received the MINT (Academic Excellence) Award 2017 from KIT for the outstanding research of 2017 academic year, Best Paper Award in the Australasian Universities Power Engineering Conference 2017, Melbourne, Victoria, Australia and Best Presentation Award in the IEEJ Branch Convention 2017, Hakodate, Japan. His research interests are renewable energy systems (especially wind power \& photovoltaic power systems), power system stability and control, microgrid and hybrid power systems, HVDC system, analysis and control of rotating electrical machines. Dr. Hazari is a member of IEEE. 